\title{
Organizational learning as a test-bed for business process reengineering
}

\author{
Larsen, Michael Holm; Leinsdorff, Torben
}

Published in:

Proceedings of the Thirty-First Hawaii International Conference on System Sciences

Link to article, DOI:

10.1109/HICSS.1998.648330

Publication date:

1998

Document Version

Publisher's PDF, also known as Version of record

Link back to DTU Orbit

Citation (APA):

Larsen, M. H., \& Leinsdorff, T. (1998). Organizational learning as a test-bed for business process reengineering. In Proceedings of the Thirty-First Hawaii International Conference on System Sciences (Vol. Volume 5, pp. 343354). IEEE. https://doi.org/10.1109/HICSS.1998.648330

\section{General rights}

Copyright and moral rights for the publications made accessible in the public portal are retained by the authors and/or other copyright owners and it is a condition of accessing publications that users recognise and abide by the legal requirements associated with these rights.

- Users may download and print one copy of any publication from the public portal for the purpose of private study or research.

- You may not further distribute the material or use it for any profit-making activity or commercial gain

- You may freely distribute the URL identifying the publication in the public portal

If you believe that this document breaches copyright please contact us providing details, and we will remove access to the work immediately and investigate your claim. 


\title{
Organizational Learning as a Test-bed for Business Process Reengineering
}

\author{
Michael Holm Larsen, M.Sc. (Eng.), Ph.D. Student \& Torben Leinsdorff, Associate Professor \\ Dept. of Manufacturing Engineering \& Dept. of Industrial Management and Engineering \\ The Technical University of Denmark,E-mail: mhl@ipt.dtu.dk\&admin@ipv.dtu.dk
}

\begin{abstract}
The fact that a company's learning ability may prevent strategic drift and the fact that many companies are undertaking BPR projects leads us to ask whether all these BPR activities promote organizational learning. Within this framework we studied the extent to which BPR promotes organizational learning by focusing on the project group and the steering committee. This paper is based partly on a theoretical study of the significant characteristics of BPR and of organizational learning and partly on a field study carried out in cooperation with the business unit of Enzyme Business, Novo Nordisk A/S. The result of the analysis is that a correlation between $B P R$ and organizational learning has been established, i.e. the BPR elements: customer focus, process orientation, high level of ambition, clean sheet principle, performance measuring, the business system diamond, and continuous improvements promote organizational learning. However, the high level of ambition, the clean sheet principle and a narrow focus on carrying out a project quickly may have the opposite effect, thereby preventing the organization from learning, and potentially failing to contribute to the avoidance of strategic drift.
\end{abstract}

\section{Introduction}

Manufacturing companies are facing increased competition and internationalization of markets and a change in customer preferences, e.g. demand for more customized products.

Like many other companies, Novo Nordisk A/S regards this as posing a risk of strategic drift. Strategic drift is a situation where a company falls out of line with its changing environment (cf. Figure 1). In fact it is not necessarily preferable just to align the changes in the environment. A new approach to the business may bring the company ahead of the general evolution of the business environment. This can be brought about by e.g. employing a new technology.

Novo Nordisk A/S aims to prevent this strategic drift by change management. The need for change management in Enzyme Business is due mainly to factors such as "price" and "time to market" [34].

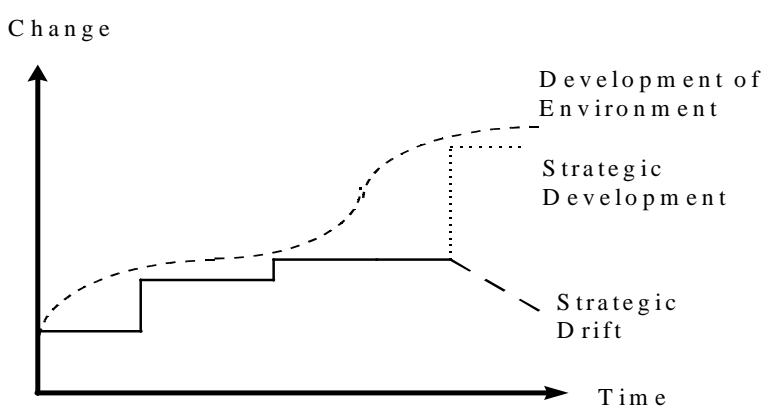

Figure 1. Strategic Drift

Source: Adapted from [21, pp.34-51].

To be able to match market requirements, Novo Nordisk A/S emphasized, in their latest strategy plan, the need for the ability to learn from and adapt to the environment [32]. Enzyme Business is eager to adapt to these conditions. During the process of change, BPR is the most commonly applied method for planning and carrying out projects at Novo Nordisk A/S.

When assisting Novo Nordisk A/S with its change management, it became evident that BPR and organizational learning are actually closely related.

Organizational learning is necessary for an organization to be able to adapt to environmental changes and to avoid strategic drift. In the literature, learning is presented as a source of competitive advantage, e.g. $[42,47,49]$. Dodgson (1993) states that organizations learn in order to improve their adaptability and efficiency during times of change, and Grantham \& Nichols (1993) state that learning enables faster and more effective responses to a complex and dynamic environment. However, definitions and mechanisms involved in achieving this advantage are not established [28]. Furthermore, little empirical evidence has been presented to support this claim. As learning is such a crucial ability for the organization, we find it relevant to use learning as a test-bed for Business Process Reengineering. This does not, however, exclude other concepts as being just as relevant as test objects. A discussion of the potential of 
Business Process Reengineering as an approach to obtaining organizational learning is therefore of interest.

This is the setting on which this paper is based. In this setting, an appropriate question is whether or not these efforts, engaged in projects according to the BPR approach, are potentially beneficial for the organization. By "beneficial" we understand improving the current situation in the direction of meeting market demands. In other words, we shall discuss how, and to what extent, the BPR philosophy may contribute to organizational learning. Focus will be placed on the project group and the steering committee during the project initiation, analysis and redesign phases of the BPR project.

In order to be able to discuss this matter we shall first present the basis for the assessment.

\section{Basis for the assessment}

This article is an attempt to assess the BPR philosophy as a vehicle for organizational learning. The basis for this assessment is a study of the literature concerning the theory of BPR and organizational learning. Participation in a concrete BPR project with Novo Nordisk A/S has also assisted us in the understanding of this concept on an empirical basis.

\subsection{Theoretical approach}

The approach to the analysis is a deductive study of the elements of which the BPR philosophy and the organizational learning consist: in other words, an investigation into which BPR elements promote the elements of organizational learning.

The results of this study were then applied to the empirical material from Novo Nordisk A/S [23] in order to establish whether/how the BPR elements promote the elements of a learning organization.

\subsection{Empirical approach}

Our role at Novo Nordisk A/S was to work with the internal BPR consultants as peers in the BPR project "Solids". "Solids" refers to the production of "solid" enzymes.

Active participation in the Solids project and involvement in the discussion of the BPR project portfolio gave us an empirical insight into how a BPR process actually takes place. This contributed to an understanding on an empirical basis - of the interaction between a BPR process and organizational learning.

\section{Basic concepts}

\subsection{Business Process Reengineering}

Business Process Reengineering (BPR), also know as Business Process Redesign [9], or Process Innovation [8], is a concept within the field of change management which to a large extent is undertaken by industry as well as by public services, e.g. [56,57]. A basic distinction of change management methods is that between incremental and radical methods. BPR is categorized as a radical method, e.g. [17, p. 32]. Another distinction is whether a method deals with processes or functions in the organization. During the last decade the tendency of management methods has shifted to addressing process-related methods, e.g. [12,38,53].

Process-oriented change management methods can be classified by their project breadth and level of ambition (cf. Figure 2). The project breadth identifies the activities which are included in the change management project.

For a company with limited problems, a change in a single process can be sufficient. A narrow approach like this cannot, however, produce the kind of substantial results needed by many companies today. The level of ambition indicates the potential of the method applied. However, the potential is closely bound to the risk involved in adopting a project with a certain level of ambition.

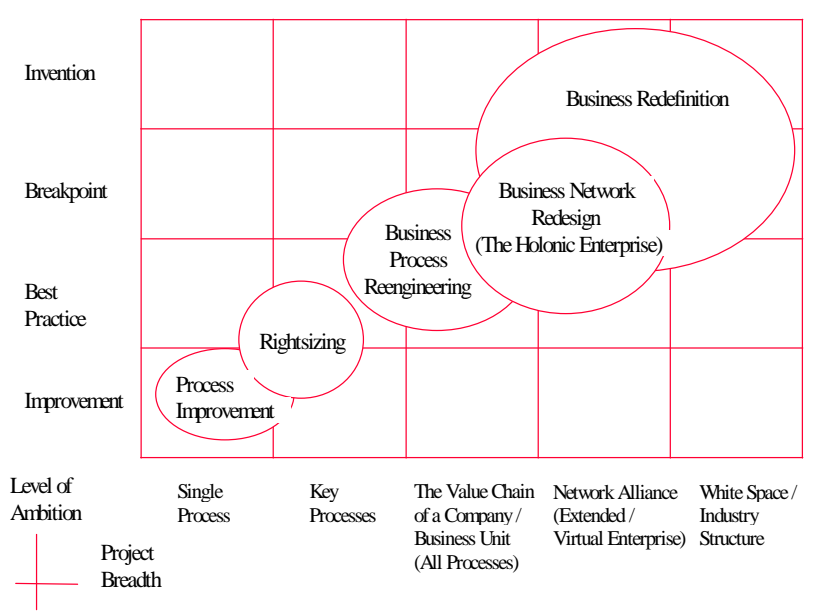

Figure 2. Level of Ambition and Project Breadth of a Change Management Method

Source: Derived from $[14,26,44,52,53]$.

Figure 2 suggests that BPR contains Benchmarking, e.g. elaborated in $[6,7,45]$, as an integral activity. BPR primarily addresses "breakpoint" and "best practice" within the whole value chain of a business unit.

Numerous definitions of BPR are found in the literature, e.g. in $[5,8,9,20,25,29,48]$. However slightly 
different the definitions, they all agree that the processes start with the customer and their satisfaction. In other words, what the company needs to do is, as Katzenbach et al. (1995) put it: to "absorb the customer's point of view".

By the BPR philosophy we understand [19, p.49]:

a systematic approach with the purpose of obtaining dramatic and permanent improvements (i.e. a high level of ambition) in customers' satisfaction related to such factors as time, quality, cost and service by analyzing and reconstructing - on a clean sheet principle - the strategically most important cross-functional business processes supported by: innovative use of information technology; new, process-oriented organizational principles, (which are created with respect for the business system diamond); process oriented performance measurements and - after implementation - maintained by continuous improvements.

This is a rather comprehensive definition. However, it contains the elements by which BPR is categorized. The most important is the process orientation of business activities. We believe that the values preferred by customers are not restricted to those mentioned. The customers must be regarded individually. The relevant values will thus differ from customer to customer. This opinion is also shared by [18]. In the case of Novo Nordisk A/S, one of the relevant factors is delivery at the time agreed, and not simply having a short delivery time in general [31].

Another characteristic of BPR is the clean sheet principle. By this we understand the building up of the organization from scratch without any restrictions imposed by existing structures, procedures, power bases or cultures. This does not mean that the reengineering team "forgets everything that they have learned from childhood", as several critics of the concept point out, but simply that one may "build the factory in an open field" [23] without having to consider the given restrictions of the organization. All this is to obtain an optimal solution. For us, as opposed to [15], the principle does not stop here. We believe that the next step should be to moderate the solution to fit into today's reality. The optimal solution, which is generated through the first step of the clean sheet principle, is very important in indicating the boundaries of a potential solution. In other words, the optimal solution becomes the new guideline for the BPR project. This idea has also won considerable influence due to the embrace of a more pragmatic approach by the companies [16, p.13].

A third characteristic is the business system diamond. By this we understand the relationship between business processes, jobs and structures, management and measurement systems, and values and beliefs, which are described below and illustrated in Figure 3.

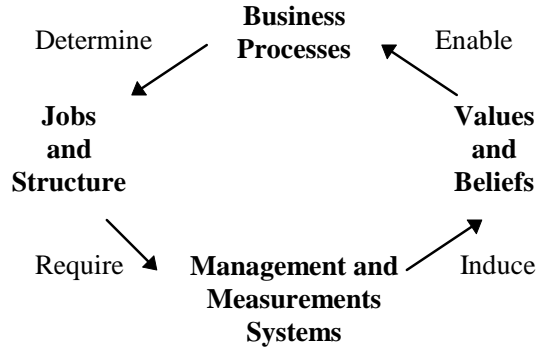

Figure 3. The Business System Diamond

Source: McManus (1995).

When restructuring the business process, the content of jobs and of organizational structures changes for all employees, including the middle managers. These changes are e.g. according to the principles of holism, information technology and cross-functional teams. Changing jobs and structures require changes in management principles and performance measurement systems. These new management principles and performance measurement systems induce change in values and beliefs, which enable the business processes. Consequently, reengineering an enterprise is not complete until all elements have changed.

\subsection{Organizational learning}

Many suggestions concerning organizational learning can be found in the literature. Argyris \& Schon (1978:2) defined organizational learning as "the detection and correction of error". Swieringa (1992:19) regards organizational learning as the changing of behavior and Fiol \& Lyles (1985:803) define learning as "the process of improving actions through better knowledge and understanding". Equally important to the organizational ability to learn is the ability to unlearn, i.e. the organization must be able to forget some of its past and earlier practice [36,41].

The basis of organizational learning is learning by its various individuals. Individual learning is a necessary but not a sufficient condition for organizational learning [51, p.33]. When this individual learning is made part of the organization itself, of its philosophy, its principles for management and leadership etc., organizational learning occurs, i.e. diffusion of leaarning. This organizational learning is, however, more than the sum of the learning of the various individuals because of synergy $[10,11]$.

By "organizational learning" we understand the cognitive and behavioral changes in an organization which occur as a result of its experiences from the interaction with its environment.

We regard organizational learning as a phenomenon which occurs whether or not the organization puts special efforts into controlling it. This learning could be beneficial, indifferent, or preventive for the organization. 
Organizational learning is thus regarded as a neutral concept [2]. With these considerations in mind, and with respect to organizational learning as a factor for the avoidance of strategic drift, we now discuss the appropriate approach to this subject.

Organizational learning will be considered in this discussion as an appropriate and constructive concept which is beneficial to the organization. This view is also shared by [47, p.19].

The individual learning is made part of the organization primarily by shared visions and group learning. Shared visions are developed when people truly share a vision, thereby being connected and bound together by a common aspiration [47, pp.205-211]. Group learning is the process of aligning and developing the ability of a team to create the results which its members truly desire [47, p.235).

Organizational learning takes place partly as single loop learning and partly as double loop learning. Single loop learning (SLL) occurs when the organization asks itself: "Do we act in the right way?", and as a consequence finds areas where it needs to be more efficient [3]. Hence, their current actions are in question (cf. Figure 4). Double loop learning (DLL) takes place when the organization asks: "Do we do the right things?", thereby opening its own basic assumptions to debate (cf. Figure 4). This is a procedure which should lead to a higher organizational effectiveness [3]. The fundamental difference between these two kinds of learning is illustrated in Figure 4 by the solid lines.

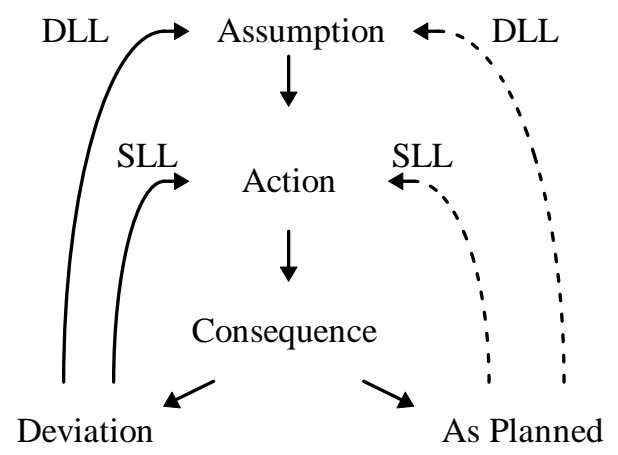

Figure 4. Single and double loop learning

An organization which is aware of and able to carry out both single and double loop learning is an organization commanding deutero learning, i.e. it is able to learn how to learn [4]: an ability which is decisive for the ability of an organization to adapt to environmental change.

Even though an organization, as a result of its actions, acquires planned results, attention should be paid to longer periods of positive feedback from the environment because this may block learning [1]. This implies that SLL and DLL should be applied periodically in order to question actions and assumptions. This is indicated be the dashed lines in Figure 4.

Single loop learning is found nearly all organizations, but few organizations experience double loop learning. This is due to the fact that organizational members resort to defensive routines in order to "avoid vulnerability, risk, embarrassment, and the appearance of incompetence" [4, p.80]. This can be attributed to the difference between what people say, i.e. "espoused theory", and what they actually do, i.e. "theory in use" [4]. Double loop learning can be applied to bridge the gap between theory and practice.

The basis of organizational learning is - as mentioned above - the learning of the various individuals of the organization. For individual learning, three factors are decisive:

(1) The ability of the individual in systems thinking. Systems thinking is seeing interrelationships rather than linear cause-effect chains and seeing processes of change rather than snapshots [47, p.71].

(2) The individual's personal mastery of his or her job. Personal mastery of one's job is to approach it from a creative as opposed to a reactive viewpoint [47, p.41].

(3) The individual's ability to free him- or herself from mental models of self or the environment. Freeing oneself from one's mental models is challenging one's basic assumptions of oneself and the environment, and changing them if necessary [47, p.154].

A precondition for obtaining a creative approach to a job is that the individual can overcome inherent feeling of powerlessness and unworthiness when trying to realize his or her visions about the job, and find strength enough to realize the visions. See also Figure 5, where the distance between the "belief in powerlessness or unworthiness" and the current situation is the emotional tension. The distance between the current reality and the vision is the creative tension.

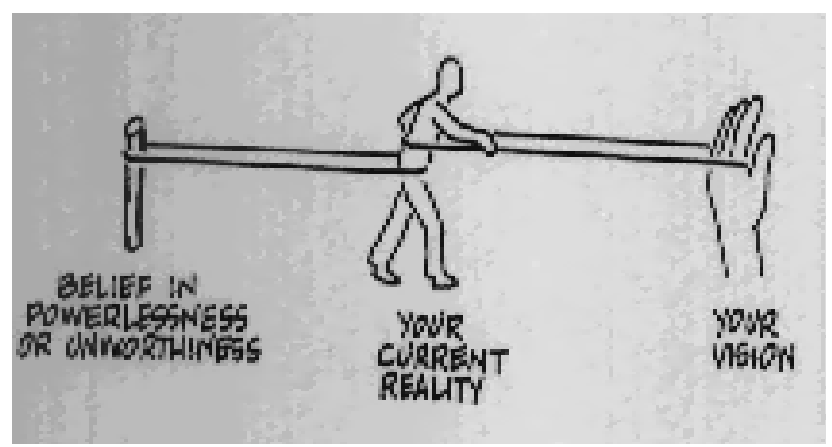

Figure 5. The individual's emotional and creative tensions

Source: [47, p.157]. 
In the first instance, Figure 5 should be regarded as a type of equilibrium, where the elastic bands between the pole and the man and the man and the hand are stretched but without tension. If the vision is changed to a higher level, i.e. the hand is moved forward, then the tension in the band between the man and the hand will increase. This will stimulate the man to move toward his own vision. However, the more he moves toward his own vision, the more he will find himself in an "unexplored and risky territory" which may stimulate his belief in powerlessness or unworthiness, i.e. increase the tension in the band between the pole and the man. At some point, if this scenario is continued, one of the bands will break and the man will either meet his vision or be drawn away from his current reality and away from his own vision.

After introducing the elements which we assign to the concept of BPR and organizational learning, we shall introduce the case study before proceeding to the discussion of how and to what extent the BPR elements promote the elements of organizational learning.

\section{The field study at Novo Nordisk A/S}

The primary activities of Novo Nordisk A/S are within the business units of Health Care Business and Enzyme Business (EB). Novo Nordisk A/S is the world's leading producer of insulin and diabetes products, and also the biggest producer of industrial enzymes.

Since 1994, Novo Nordisk A/S has been undertaking BPR activities in both business units.

\subsection{BPR at Enzyme Business}

In Enzyme Business, the BPR activities are coordinated by the EB BPR Group. The EB BPR Group holds a portfolio of complementary BPR projects. Several projects are executed in parallel according to resources and emerging areas of focus. Each project in the BPR project portfolio of Enzyme Business can be split up into the following four phases: project initiation, analysis, redesign, and implementation and follow-up.

Project initiation is primarily the development of the mandate which indicates the scope and the goals of the BPR project. Planning and organizing the projects as well as recruiting key employees are also included.

During the analysis phase, relevant data are collected, e.g. process documentation and interviews. The first milestone in a BPR project is the presentation of a "Baseline report" which documents the analysis phase by describing the business process regarded AS IS.

In the redesign phase, new organizational approaches are addressed, e.g. by studies of comparative businesses, i.e. benchmarking of best practice, and by the clean sheet principle which is performed iteratively to train those involved in making redesign proposals without any close ties to the existing organization. The second milestone in a BPR project is a "Blue Sky report", which describes the results of the redesign and indicates which is the business process TO BE.

The results of the redesign phase are implemented in the organization and followed up sequentially by continuous improvements. Implementation is carried out in the relevant line of business and assisted by the steering committee to secure implementation of the findings and, if necessary, to evaluate potential modifications to the solution found during the redesign.

The BPR Group took the initiative of establishing a forum, called Umbrella, for the directors, executives, and the BPR Group of Enzyme Business. The purpose of this forum was to inform, coordinate and transfer knowledge between projects throughout the business unit. It was also important to have a forum to discuss the often critical matters which emerge during a BPR project.

\subsection{Aspects of the Solids project}

The organization of the BPR activities in the Solids project consisted of a project group and a steering committee. The project group employed the internal BPR consultants, foremen from the production line, senior chemists, and external consultants. The steering committee was designated to evaluate the work and findings of the project group. This group consisted of directors of the organizational areas involved and the manager of the BPR Group. The steering committee reported to the Senior Management Group in EB.

The mandate of the Solids project was an integrated production process with high productivity gains and few products off specification. In the beginning of the analysis phase, the project group found it necessary to re-evaluate the scope of the mandate due to the process consideration of the BPR approach. The analysis of the initial process had a duration of three months and the redesign phase was two months.

The ideal solution of the Solids project was to have all activities integrated at one geographical site. However, when considering the actual costs incurred in doing so, the fermentation stayed separated from the rest of the process. 
The results of the project were: establishment of process orientation and process owner, significantly shorter lead time, resource reduction, extended tapping capacity to 24 hours, on-line process control, elimination of intermediary stages in the production process, proactive planning, and a re-evaluation of the product portfolio. The above BPR case is the foundation upon which the discussion will be based.

\section{The relationship of BPR to organizational learning}

When studying how and to what extent the BPR philosophy may contribute to organizational learning, the following questions should be considered:

- Does BPR make systems thinking possible?

- Does BPR promote the individual's personal mastery of his or her job?

- Does BPR promote the ability of individuals to free themselves from their existing mental models?

- Does BPR promote diffusion of the learning of various individuals throughout the organization?

- How are shared visions created in a BPR project?

- How does BPR promote group learning?

- Where in a BPR project - if at all - do single loop and double loop learning take place?

These questions will be answered in the following sections. This discussion will be structured after the learning elements and the phases of a BPR project. The following sections contain theoretical deductive considerations as well as empirical observations and insight primarily related to the Solids project.

We categorize the importance of a learning element in a specific phase of a BPR project as high, medium or low in order to be better able to distinguish the learning elements required of the project group as well as the steering committee. An argumentation for the values stated will be provided. The observations of the Solids project and their potential divergence from the theoretical findings are then presented and discussed. The steering committee's and the project group's comprehension of the concept and the supporting tools are also presented.

A general characteristic is that the steering committee needs to be able to master all of the learning elements in the project initiation phase, and then to maintain these throughout the project. The project group is established towards the end of the first phase. Hence, they are not actively involved in this phase.

Note that the empirical insight does not cover the implementation phase which was carried out in the production line. However, all of the learning elements have to be addressed in the first three phases - and subsequently maintained during implementation - to acquire organizational learning in the BPR project.

\subsection{Systems thinking}

5.1.1. Expected findings derived from theory: $B y$ stressing the process viewpoint and the need for combining various partial processes into one logical cross-functional business process, the BPR philosophy provides systems thinking.

For the steering committee, the systems thinking must be at a high level during project initiation, because it is here that the mandate (the goals and scope) of the project group is decided. During the analysis and redesign phases the steering committee needs only to apply systems thinking on a medium level, due to its primary job, which is to monitor the work of the project group. In the implementation and follow-up phases, the systems thinking also needs only to be maintained from the previous phases, i.e. on a medium level.

For the project group, no systems thinking is relevant during project initiation. This is due to their time of recruitment. In the next phases the group's systems thinking must be on a fairly high level in order to cope with the complexity of the business process.

5.1.2. Findings in the concrete project: When comparing these theoretical considerations with our experiences from the Solids Project, we found the following:

(1) The general need for systems thinking in a BPR project was confirmed.

(2) The indicated theoretical levels needed for systems thinking in the steering committee and the project group in the various phases were confirmed.

(3) All the employees, given an opportunity to practice systems thinking, were fond of this opportunity because it gave them a more in-depth understanding of the organization and their own role in it.

(4) Process orientation made the project group see the need to work with all of the production process for enzymes rather than only one segment. The consequence was that the original mandate of the Solids Project had to be broadened by the steering committee in order to avoid sub-optimization.

(5) To provide systems thinking about a complex process is not easy and must be supplemented by relevant tools. In the EB project portfolio, simulation was applied to the business processes to establish an understanding and diagnosis of information and material flows, bottlenecks and other obstacles. This gave new insight into the causes of various problems. As a tool for understanding the complexity of the product portfolio, an $\mathrm{ABC}$ analysis (a Pareto analysis [24, p.109]) was used, showing the tail of products giving only a marginal profit contribution but binding a lot of production resources. This led to some 
serious considerations regarding a reduction in the number of such marginal profit contributors.

In summary, the process orientation promotes a holistic understanding of the organization. Tools such as simulation, IDEF0 and data flow diagrams assist comprehension of the complexity of the organization. Hence, the systems thinking is promoted by BPR.

\subsection{Personal mastery}

5.2.1. Expected findings derived from theory: The BPR philosophy is to create dramatic improvements in customer satisfaction. This is only possible by formulating very ambitious goals as visions for the BPR project during project initiation.

The steering committee must therefore show a high degree of personal mastery of its job during project initiation. In the analysis phase the demand for personal mastery is low, due to the fact that the vision of the project is already set, and most work is carried out by the project group. In the redesign phase, the demand for personal mastery is on a medium level because the steering group must evaluate the proposals of the project group. During the implementation many problems will arise, primarily because of resistance to change. Here, the steering group must play a leading role in ensuring that the planned reorganization actually takes place [14], and it must again show a high degree of personal mastery.

In the analysis phase, the project group will work mainly on mapping the existing organization, and the demand for personal mastery will be medium. In the redesign phase, however, the demand for personal mastery will be on a high level because it has to meet the high level of ambition of the BPR project. In the implementation phase, the demand for personal mastery will again be on a medium level, because ensuring implementation of the reorganized processes will be primarily the responsibility of the steering committee.

5.2.2. Findings of the concrete project: When comparing these theoretical considerations with the experiences from the Solids project we found the following:

(1) The general need for a high degree (at least at a medium level) of personal mastery in the steering group and the project group was confirmed.

(2) The steering committee was quite able - during project initiation - to formulate visionary demands for the future processes and to maintain these visions in the following phases.

(3) The analysis phase demonstrated that, in practice, it is often impossible to separate the analysis and the redesign phases. Most of the fundamental ideas for redesign were actually generated during the analysis phase.
(4) The personal mastery of the project group was strong enough to cope with the problem that it was impossible, within the framework of the Solids project, to cope with the goals stated, even though the scope was extended. The project group formulated the foundation for the necessary radical solution and gave recommendations to other project groups within the BPR project portfolio.

(5) Personal mastery is heavily influenced by the corporate culture. A foreman who was a member of the project group and could see his job being eliminated in the reorganized process demonstrated enough personal mastery to be able to say: "Well, I am not employed by department 038, I am with Novo Nordisk". Such an attitude and personal mastery is only possible in an organizational culture which stresses that employment is with the firm, and not in a specific department.

(6) To demonstrate sufficient personal mastery in a BPR project is - on the other hand - not easy. This is due to the creative tension which quickly becomes high when ambitious goals must be met. Individuals therefore risk failing to match the goals of the project. In the Solids project it was found expedient several times to repeat the "green field approach", i.e. the clean sheet principle, thereby slowly moving the current reality of the steering group and project group towards the vision. An alternative approach could be to modify the extremely radical goals of the BPR project [16 vs. 15].

In summary, the BPR element "high level of ambition" promotes personal mastery by extending the individual's vision. By doing this, the individual risks exceeding his or her own abilities.

\subsection{Mental models}

5.3.1. Expected theoretical findings: A BPR project, with the importance given to customer focus and process organization, is quite a challenge to the existing mental models of the steering committee and project group. Indeed, both groups must have the ability to free themselves from their previous mental models if they are to meet the demands of a BPR project.

5.3.2. Findings of the concrete project: When comparing these theoretical considerations with our experiences from the Solids project we found:

(1) The BPR philosophy introduces a new important mental model. However, it does not go any farther, and it does not give any directions. Neither does it ensure that all the necessary changes in the mental models of the employees involved in a BPR project actually occur. It was only confirmed that it will often be expedient to use outsiders in the project group to ensure new viewpoints and to make the project group learn quickly and apply new approaches. 
(2) The use of external/internal consultants made it easier for both steering and project group to change their mental models. This suggestion experience is also shared by [50, p.130], however, in a system development context.

(3) The use of the green field approach encouraged a change within the existing mental models.

(4) Encouraging change of the mental models is often a very difficult process. This was evident especially in relation to the steering committee, which had great difficulties setting a proper scope for the Solids project in the first place. The steering committee was also unaware that the subsequent revision of the scope had to actively involve employees from the extended working field in the project group.

In summary, the customer focus and the process orientation promote new mental models in a BPR project by providing new approaches for organizing the activities of the organization.

\subsection{Deutero learning}

5.4.1 Expected theoretical findings: During a BPR project, both single and double loop learning are required, but at different phases.

When formulating the vision for the future organization, the steering group must double loop-learn by questioning its own assumptions to obtain a vision with radical implications.

When mapping the existing activities during the analysis phase, there is a need primarily for single loop learning to do the analysis and evaluate the findings.

During the redesign phase both steering committee and project group must make many single and double loops in order to design the best possible solution.

During implementation the project group must make the final adjustments to fit the reengineered process to the actual working conditions, i.e. optimizing through single loop learning. During and after the implementation the new process owner should take care of the continuous improvements in order to maintain the business process: cf. the definition of [19].

5.4.2. Findings of the concrete project: When comparing theory with our experiences in the Solids project we found the following:

(1) The statements above were confirmed during the BPR project.

(2) The BPR philosophy does not explicitly distinguish between single loop and double loop learning. To some extent this hampers the use of double loop learning and the continuous interplay in the organization between single and double loop learning.

(3) Double loop learning takes a lot of time (cf. the example with the green field approach). This is especially evident when an iterative approach is needed in order to expand the creative tension of the project group members. (4) It is quite a challenge, and very often individuals and groups will hesitate to perform double loop learning to an extent that is actually necessary. The change of scope initiated by the project group in EB mentioned above became necessary because the steering group did not originally do the required double loop learning.

In summary, the clean sheet principle and continuous improvements promote deutero learning.

\subsection{Shared visions}

5.5.1. Expected findings derived from theory: The BPR philosophy works in visions. A typical BPR vision is e.g. to reduce throughput time by $50 \%$. A basic concept of the BPR philosophy is thus the handling of shared visions.

However, the problem of such a vision is that it is too concrete and time-oriented. When this visionary goal is met, it disappears as a vision and a new one has to follow to maintain the momentum. Goals therefore have to be of a kind which is impossible to reach, but which can be approached step by step. The BPR philosophy provides a vision of this kind, i.e. the permanent and important shared vision for the organization, i.e. the customer focus and the importance of customer satisfaction. These visions prevent concrete and time-oriented goals from gaining too much influence.

The customer focus and the importance of customer satisfaction should be stressed by the steering committee during project initiation, and by the project group when analyzing and redesigning the business processes. The customer focus should also be maintained during implementation.

5.5.2. Findings of the concrete project: When comparing these theoretical considerations with our experiences with the Solids project we found:

(1) Initially, some of the members of the project group had some difficulty with the distinction between internal and external customers. The external customers were rarely considered and focus was placed on how to optimize their own job in order to be able to deliver to the next stage in the production. Long discussions in the project group led to focusing on the end recipient of the product.

(2) In general, Novo Nordisk A/S has a clearly defined strategy, and they put a lot of effort into communication of the purpose and strategy of the company. A strategy exists for the next year, the next 3-5 years, the next 10 years, and the next 100 years. This strategy is communicated through handouts, on posters, put into frames on walls, and on carton houses etc. This 
substantial amount of communication promotes the shared vision in general in the organization.

In summary, the customer focus promotes the shared visions of the organization.

\subsection{Group learning}

5.6.1. Expected theoretical findings: The high ambition level of a BPR project cannot be realized without group learning in both the steering group and the project group.

When the ideas of the BPR project group are implemented, the company takes the form of a process organization with cross-functional teams. In this system, performance measurement has to be designed in correspondence with the redesigned business processes in order to adapt to the new working conditions. Otherwise the employees will not be measured according to what they actually do, and there is a risk that crucial tasks will not be executed.

5.6.1. Findings of the concrete project: When comparing these theoretical considerations with our experiences with the Solids project we found:

(1) The assumptions above were to some extent confirmed. However, a measurement system based on performance and a group assessment were not designed for all relevant persons in the organization.

(2) We also found that group learning in both steering group and the project group was promoted by supplementing the project group with outsiders who brought with them a structured methodology and specific tools for solving the problems found. The insiders were the experts regarding experience.

In summary, the performance measurements promote group learning.

\subsection{Diffusion of Learning}

5.7.1. Expected theoretical findings: Diffusion of information in a BPR project starts in the analysis phase. In this phase as well as the redesign phase, substantial amounts of information must be exchanged within the organization in order to be reorganized effectively.

This broad diffusion does not, however, take place until the principles of the business system diamond are applied. This implies that not only the business processes, but also jobs and structures, management principles and measurement systems as well as values and beliefs are changed.

The process organization also promotes diffusion of individual learning by establishing autonomous work teams with the responsibility for reacting quickly to customer demands. The process organization is thus a vehicle which by its very nature is ready for quick diffusion of individual learning: a process which can be quickened by performance measurements and the use of information technology for assembling, sharing and exchanging the new knowledge.

5.7.2. Findings of the concrete project: When comparing these theoretical considerations with our experiences with the Solids project we found:

(1) With respect to the Business System Diamond only the "business processes" and "jobs and structure" were fully aligned. This will be a potential problem during the implementation.

(2) The demand for diffusion of information about the Solids project was also found to be very high. One way of meeting this demand was to create a forum, called Umbrella, consisting of the vice-president of the Enzyme Business and his closest executives. The purpose of the forum was to share ideas and experiences with the various BPR projects. Another way of meeting this demand was to send newsletters dealing with the current BPR activities throughout the organization.

In summary, the business system diamond promotes the diffusion process.

\section{Lessons learned}

In practice, the organizational learning elements are difficult to distinguish from each other because they are highly interrelated. The lessons learned will therefore address organizational learning as a concept without pinpointing the specific elements.

We indicate below a few recommendations regarding the application of Business Process Reengineering for organizational learning. These recommendations are:

- to double loop-learn in setting the mandate and during the reengineering phase.

- to establish an overall unit for discussion and diffusion of experiences regarding BPR projects at the top of the organization.

- to involve the relevant line of business during all activities, starting from analysis.

- to apply the clean sheet principle iteratively.

- to explicitly address learning elements during the BPR project. This suggestion also finds support in [50, p.129], but in a more IT-oriented context.

- to avoid a narrow focus in carrying out a BPR project quickly.

\section{Conclusion}

In this paper we have argued for the rational approach in adopting organizational learning as a test-bed for change management initiatives due to a need of a 
company to adapt to environmental changes. It is then noted that BPR projects are undertaken by companies to a large extent. By applying the organizational learning testbed to BPR, we then suggest to what extent BPR promotes organizational learning.

Our suggestion is based on theoretical findings and on empirical insight from the Solids project of Enzyme Business, Novo Nordisk A/S. It is not, however, statistically confirmed.

We have argued that systems thinking is promoted by BPR due to the fact that process orientation promotes the holistic understanding of the organization. We also suggest that various tools can help to understand the complexity of the organization. A high level of ambition promotes personal mastery by extending the individual's capabilities and vision. The customer focus and the process orientation promote new mental models through new approaches for organizing the activities of the organization. Deuterolearning is promoted by BPR due to the fact that the clean sheet principle provides a possibility for double loop learning and continuous improvement is actually the definition of single loop learning. The customer focus promotes the shared visions of the organization as it delivers an obvious fixed point of focus. Performance measurements promote group learning as employees work in groups and as they will then be measured according to what they actually do at a group level. Finally, the business system diamond promotes the diffusion process because all elements in the diamond are addressed.

On this basis we conclude that BPR - by its customer focus, high level of ambition, process orientation, clean sheet principle, performance measuring, business system diamond and continuous improvements - promotes a learning organization.

However, the opposite effect may occur, as the high level of ambition also risks exceeding the individual's own capabilities, and as the clean sheet principle does not guarantee a paradigm shift, but provides only the possibility. Hence, the high level of ambition and the clean sheet principle may prevent the organization from learning.

A narrow focus on quickly carrying out a project was also found to have a preventive effect with respect to organizational learning.

These considerations have to be kept in mind in order to address all organizational learning elements in a Business Process Reengineering project. Hence, BPR when applied with caution regarding the above pitfalls may prevent strategic drift and offer a gain in competitive advantage.

We have thus demonstrated a relevant correlation between Business Process Reengineering and organizational learning, by suggesting Business Process Reengineering as a potential approach to obtaining organizational learning and to dealing with today's rapidly changing environment.

\section{Implications for further research and development}

This paper suggests that BPR promotes organizational learning when carried out with caution, but whether or not organizational learning prevents strategic drift, or promotes strategic competitive advantage, is an open question. Several attempts have been made to quantify how to gain decisive competitive advantage, e.g. by industrial analysis focusing on structural features $[39,40]$ or by a resource-based view of the firm, focusing on skills and capabilities, e.g. [55].

Recently, management contributors, academic as well as popular, have emphasized "the individual" and "knowledge" as determinants of competitiveness. For example, [37] proposed that effective management of people, i.e. developing and empowering people, sharing information, creating self-managed teams, and training and cross-training people, is a more significant approach to gaining competitive advantage than industrial analysis.

Learning is stimulated both by environmental changes and by internal factors, e.g. individuals, culture, structure, strategy, etc., in a complex and iterative manner. BPR primarily affects internal factors in order to satisfy external requirements.

Organizational learning is influenced by strategy in the sense that this limits decision making and represents a context for the perception and interpretation of the environment. The strategic options chosen by the organization depend on the learning capacity of the organization. Organizational culture, i.e. beliefs, ideologies, values, norms, and the quantity of resources in the organization also determine the quality and quantity of learning.

The literature as well as this paper do not offer sufficient empirical evidence as to whether or not organizational learning is an "enabler" in preventing strategic drift. More focus on how to prevent strategic drift or attain competitive advantage is therefore needed.

We have found that BPR and organizational learning correlate well. One explanation might be that BPR and organizational learning - in the way they are presented here - are both systematic approaches to interpreting organizations. More attention should therefore be paid to extending the concept of organizational learning to avoid the restrictions imposed on learning by a systematic approach. An interesting recent analysis of the problem of obtaining learning during advanced systems development is provided by [50]. These findings seem to some extent to be in line with our results, although they are syntheses. 
Another area for further research is how to support the learning processes and communication in general with Information Technology, e.g. through investigation of developments within Computer Supported Cooperative Work (CSCW).

\section{Acknowledgments}

The authors are very grateful to Enzyme Business BPR Group and the other people involved in the study at Novo Nordisk A/S for the unique opportunity they offered us to carry out the project.

We are also grateful to Zenia Vittarp, Manager of EB BPR Group, and internal consultant Christian Wieth, for their constructive criticism during the preparation of this paper. Our thanks to Mikkel Roulund for participating in the preliminary research.

\section{References}

[1] Argyris, C., "Good Communication that Blocks Learning", Harvard Business Review, July-August, 1994, pp. 77-85.

[2] Argyris, C., On Organizational Learning, Blackwell, Cambridge, Massachusetts, 1992.

[3] Argyris, C. \& D. Schön, Organizational Learning: A Theory of Action Perspective, Addison-Wesley, 1978.

[4] Argyris, C. \& D. Schön, Organizational Learning II Theory, Method, and Practice, Addison-Wesley, 1996.

[5] Burke, G. \& J. Peppard, Examining Business Process Reengineering - Current Perspectives and Research Directions, The Cranfield Management Series, 1995.

[6] Carr, D.K. \& H.J. Johansson, Best practices in reengineering, McGraw-Hill, 1995.

[7] Camp, R.C., Benchmarking - The search for industry best practices that lead to superior performance, ASQC Quality Press, 1989.

[8] Davenport, T.H., Process Innovation, Harvard Business Press, Boston, MA, 1993.

[9] Davenport, T.H. \& J.E. Short, "The new Industrial Engineering: Information Technology and Business Process Reengineering", Sloan Management Review, Vol. 31, No. 4, Summer, 1990, pp. 11-27.

[10] Dodgson, M., "Organizational learning: A review of some literature", Organization Studies, 14/3, 1993, pp. 375-394.

[11] Fiol, C. M. \& M.A. Lyles, "Organizational Learning", Academy of Management Review, 10/4, 1985, pp. 803-813.

[12] Franchis, A. \& G. Southern, "Epochs and institutions: contextualising BPR", New Technology, Work and Employment, Vol. 10, No 2, September, 1995, pp. 110-120.
[13] Grantham, C.E. \& L.D. Nichols, The digital workplace: Designing Groupware Platforms, New York, Van Nostrand Reinhold, 1993.

[14] Hall, E.A., J. Rosenthal \& J. Wade, "How to make Reengineering Really Work", Harvard Business Review, 1993, November-December.

[15] Hammer, Michael, "Reengineering Work: Don't Automate, Obliterate", Harvard Business Review, 1990, July-August.

[16] Hammer, Michael, Beyond Reengineering, Harper Business, 1996.

[17] Hammer, M. \& J. Champy, Reengineering the Coopertion A Manifesto for Business Revolution, Nicholas Brealey Publishing, 1993.

[18] Hammer, M. \& S.A. Stanton, The Reengineering Revolution, Harper Business, 1995.

[19] Hviid, J. \& K. Sant, Business process Reengineering Fokus på forretningsprocesser, (Danish), Børsens Bøger, 1994.

[20] Johansson, H.J. \& P. McHugh, A.J. Pendlebury \& W.A. Wheeler III, Business Process Reengineering - Breakpoint Strategies for Market Dominance, Wiley, 1993.

[21] Johnson, G. \& K. Scholes, Exploring Corporate Strategy, Prentice Hall, 1993.

[22] Katzenbach, J.R., F. Beckett, S. Dichter, M. Feigen, C. Gagnon, Q. Hope \& T. Ling, The Real Change Leaders, Nicholas Brealey Publishing, 1995.

[23] Larsen, M.H., M. Roulund \& T. Leinsdorff (superviser), Forandringsledelse $i$ et BPR-perspektiv - mod laring $i$ organizationen? (Danish), Masters Thesis, Department of Industrial Management and Engineering, The Technical University of Denmark, 1996.

[24] Leinsdorff, T., Økonomistyring for driftteknik-kere, (Danish), Handelshøjskolens Forlag, 1992, p. 109.

[25] Loewenthal, J.N., "Reengineering the organization: a stepby-step approach to corporate revitalization", Quality Progress, Vol. 27, No. 2, February, 1994, pp. 61-63.

[26] McHugh, P., G. Merli, \& W.A. Wheeler III, Beyond Business Process Reengineering - Towards the Holinic Enterprise, John Wiley \& Sons, 1995.

[27] McManus, J.J., An Implementation Guide on How to Reengineer Your Business", Stanley Thornes, 1995.

[28] Moingeon, B. \& A. Edmondson (edit.) Organizational Learning and Competitive Advantage, SAGE Publications, London, 1996.

[29] Morrow, M. \& M. Hazell, “Activity Mapping for Business Process Redesign", Management Accounting, Vol. 70/2., 1992, February, pp. 36-38.

[30] Novo Nordisk A/S, Enzymer - hvor de bruges, (Danish), 1995.

[31] Novo Nordisk A/S, "Customer Perception Study", Internal Document, 1996a. 
[32] Novo Nordisk A/S, "International Meeting at Novo Nordisk A/S in October", Internal Document, 1996b.

[33] Novo Nordisk A/S, Annual Report 1995, 1996c.

[34] Novo Nordisk A/S, "Enzyme Business Strategy", Internal Document, 1996d.

[35] Novo Nordisk A/S, Annual Report 1996, 1997.

[36] Overell, S., "Learning to unlearn for a flexible future", People Management, 1996, May 2.

[37] Pfeffer, J., Competitive Advantage Through People, Harvard Business School Press, Boston, MA, 1994.

[38] Pollalis, Y.A., "A Systemic Approach to Change Management - Integrating IS Planning, BPR, and TQM", Information Systems Management, 1996, Spring.

[39] Porter, M.E., Competitive Strategy - Techniques for Analyzing Industries and Competitors, The Free Press, 1980.

[40] Porter, M.E., Competitive Advantages - Creating and Sustaining Superior Performance, The Free Press, 1985.

[41] Prahalad, C.K. \& G. Hamel, Competing for the Future, Harvard Business School Press, 1994.

[42] Redding, J.C. \& R.F. Catalenello, Strategic Readiness: The Making of the Learning Organization, Jossey-Bass, San Francisco, CA, 1994.

[43] Reesen, L. \& J. Becker, Teknologiledelse, (Danish), 1995.

[44] Ringheim, C. \& P.E. Christensen, "Rightsizing af Engineering-Funktioner" (Danish), 1995, In Ressen \& Becker (1995).

[45] Rolstadås, A., Benchmarking - Theory and Practice, Chapman \& Hall, 1995.

[46] Scott Morton, M.S. (edit.), The Corporation of the 1990s Information Technology and Organizational Transformation, Oxford University Press, 1991.

[47] Senge, P.M., The Fifth Disipline - The Art \& Practice of The Learning Organization, Century Business, 1990.

[48] Short, J. E. \& Venkatraman, N., "Beyond Business Process Redesign: Redefining Baxter's Business Network”, Sloan Management Review, Vol. 34, No. 1, 1992, Autumn, pp. 7-21.

[49] Stata, R., "Organizational learning: The key to management innovation", Sloan Management Review, 21, Autumn, 1989, pp. 210-225.

[50] Stein, E.W. \& B. Vandenbosch, Organizational Learning during Advanced System Development: Opportunities and Obstacles", Journal of Management Information Systems, Fall, Vol. 13, No. 2, 1996, pp. 115-136.

[51] Swieringa, J. \& Wierdsma, A., Becoming a Learning Organization - Beyond the Learning Curve, Addison Wesley, 1992.

[52] Taffinder, P., The New Leaders - Achieving Corporate Transformation through Dynamic Leadership, Kogan Page, 1995.
[53] Taylor, B., Successful Change Strategies, pp. 125-141, Directors Books, 1994.

[54] Venkatraman, N., "IT-induced Business Reconfiguration", 1991, In Scott Morton (1991).

[55] Wernerfelt, B., "A resource-based view of the firm", Strategic Management Journal, 5(2), 1984, 171-180.

[56] Willcocks, L. "A Survey of current BPR Practice", 1995a. In Harvey, D. with Maletz, M. \& Willcocks, L., Re-engineering: The Critical Success Factors, London: Business Intelligence, 1995.

[57] Willcocks, L., "False Promise or Delivering the Goods? Recent Findings on the Economics and Impact of Business Process Re-engineering", 1995b, Proceedings of the Second European Conference in IT Evaluation, Henley Management College, Henley, United Kingdom, July. 